\title{
Frequency of Chlamydia trachomatis Infection in Spontaneous Abortion of Infertile Women During First Pregnancy Referred to Tabriz University of Medical Sciences by Nested PCR Method in 2015
}

\author{
Mehdi Haghdoost $^{1}{ }^{\circledR}$, Sanaz Mousavi², Mehdi Khanbabayi Gol ${ }^{3}$, Majid Montazer ${ }^{4 * \mathbb{C}}$
}

\begin{abstract}
Objectives: Chlamydia trachomatis, as the main cause of bacterial sexually transmitted disease (STD), can lead to serious complications such as spontaneous abortion. Therefore, the aim of this study was to determine the frequency of $C$. trachomatis infection in spontaneous abortion of infertile women who referred to Tabriz University of Medical Sciences during the first pregnancy by means of nested polymerase chain reaction (PCR) method in 2015.

Materials and Methods: The present descriptive, cross-sectional study was performed in the infertility clinics of Tabriz University of Medical Sciences from March 21, 2015 to March 19, 2016. A total of 120 infertile women were selected by the convenience sampling method. The specimens were prepared by the Dacron swab after four rotations in the endocervix and discharged into the specific transport medium of $C$. trachomatis. The DNA extraction was then performed by AccuPrep genomic DNA kit and the DNA was extracted until performing the PCR at $-20^{\circ} \mathrm{C}$. Next, nested PCR was conducted in 2 rounds and the final product of PCR was agar $-2 \%$ gel electrophoresis. After entering the data in SPSS, the chi-square test was used to examine the role of factors influencing $C$. trachomatis infection and a $P$ value less than 0.05 was considered significant.

Results: The incidence of $C$. trachomatis infection in women with spontaneous abortion was $16.66 \%$. In addition, there was a significant difference between the infected and non-infected groups regarding employment $(P<0.04)$, birth control method $(P<0.03)$, and the number of sexual intercourses per week $(P<0.001)$.

Conclusions: The prevalence of $C$. trachomatis in women who became pregnant with infertility treatment and spontaneous abortion was high in this study. Thus, nested PCR is considered an appropriate method for the diagnosis of C. trachomatis and it is essential for pregnant women who experience pregnancy with infertility treatment.

Keywords: Chlamydia trachomatis, Nested PCR, Infertility, Spontaneous abortion
\end{abstract}

\section{Introduction}

Chlamydia trachomatis is an obligate intracellular bacterium and the most common sexually transmitted disease (STD) across the world that can hide itself in the genital tissue (i.e., cylindrical and transitional cells) and cause unidentified asymptomatic damage to genital tubes in both males and females. In addition, C. trachomatis would be hidden until the occurrence of secondary symptoms since the symptoms of this infection are less prevalent than those of other STD infections $(1,2)$ and patients refer to a doctor at the late stages of clinical manifestations (infertility). Therefore, C. trachomatis is more severe than the other infections because of its silent manifestation and late treatment and this may lead to complicated treatment procedures (3).

According to the World Health Organization, 92 million people are added to the number of $C$. trachomatis patients annually and the infection doubles the risk of infertility and ectopic pregnancy (4). As the infection continues to be sexually transmitted, its increasing prevalence seems natural (5). Further, the rising prevalence and inadequate immunity of previously affected individuals against the infection are regarded as the main reasons for the high prevalence of such infections that would make all women, especially those following artificial insemination by donor (AID), develop this type of infection $(6,7)$.

Due to infertility and consequently high costs of AID in infertile women, studies on the factors of fetal loss including various kinds of infections have extensively focused on these women (8). C. trachomatis is one of these infections which can lead to spontaneous abortion, deformation, neonatal death, and neonatal morbidity in pregnant women. Some studies have confirmed the pathogenicity of Chlamydia in spontaneous abortion. Accordingly, focusing on this type of infection in infertile women undergoing AID is necessary and inevitable $(9,10)$. 
Furthermore, the recognition and knowledge of the risk factors are more important for this type of infection compared to the other ones since a great deal of expenses and energy is imposed on infertile women during the procedures for pregnancy. One of these factors is $C$. trachomatis infection that might be present in these women. Therefore, it is important for these women to be aware of its presence so that timely necessary treatments could be applied to prevent the complications for both mother and fetus during pregnancy. Hence, this study aimed to investigate the frequency of $C$. trachomatis infection in spontaneous abortion of infertile women during their first pregnancy by nested polymerase chain reaction method. The results of the study may pave the way for further research and explorations in this area.

\section{Materials and Methods}

This descriptive, cross-sectional study was conducted from March 21, 2015 to March 19, 2016 in the infertility clinics of Tabriz Al-Zahra hospital (i.e., Al-Zahra and Taleghani clinics). Similar to the study by Zahirnia et al (3), 120 women were selected for this study using the convenience sampling technique. The inclusion criteria were being married for at least five years, suffering from infertility confirmed by infertility specialists, being under infertility treatment over the past year, experiencing pregnancy after infertility treatments, demonstrating the symptoms of hemorrhage and back pain, along with suspected spontaneous abortion. Moreover, the exclusion criteria included having a history of chlamydia infection (woman or her husband) and spontaneous abortion, having children, and consuming antibiotics.

The subjects responded to a questionnaire which aimed to collect data about their age, education, job, the type of contraceptive, previous pregnancy, vaginal discharge, and the frequency of sexual intercourse during a week. According to Kucinskiene et al (11), after inserting a sterile speculum and after four rotations in the endocervix, the research assistant (the senior resident of obstetrics and gynecology surgery) inserted the Dacron swab (Delta lab, Spain) into the specific transport medium of $C$. trachomatis ( $0.2 \mathrm{~m}$ sucrose sulfate buffer or $2 \mathrm{SP}$ in $\mathrm{pH}=7.2$ with $10 \%$ fetal bovine serum, as well as the antibiotics 50 $\mu \mathrm{g} / \mathrm{mL}$ streptomycin, $100 \mu \mathrm{g} / \mathrm{mL}$ vancomycin, and $10 \mu \mathrm{g} /$ $\mathrm{mL}$ gentamicin purchased from Sigma, Germany). The samples were then transferred to the microbiology lab of the Faculty of Medicine at Tabriz University of Medical Sciences. All the samples were stored in a fridge at $-75^{\circ} \mathrm{C}$ until DNA extraction.

DNAs were extracted using the AccuPrep Genomic DNA Extraction Kit (Korean Company Bioneer). First, 20 $\mu \mathrm{L}$ of protease $\mathrm{K}$ and $200 \mu \mathrm{L}$ of binding buffer were added to a $200 \mu \mathrm{L}$ sample and then the mixture was incubated at $60^{\circ} \mathrm{C}$ for 20 minutes. Next, $100 \mu \mathrm{L}$ of isopropanol was added and the mixture was centrifuged at $8000 \mathrm{rpm}$ for 60 seconds. The washing buffers 1 and then $2(500 \mu \mathrm{L})$ were added to the microtubes, followed by adding $200 \mu \mathrm{L}$ of elution buffer after the centrifugation and recentrifuging the mixture at $8000 \mathrm{rpm}$ for 60 seconds. The extracted DNAs were kept at $-20^{\circ} \mathrm{C}$ until the PCR test. Table 1 presents the sequence of the primers which were used in the nested PCR for the detection of OMP1 Chlamydia (12).

The first round of nested PCR was performed as follows: First, $50 \mu \mathrm{L}$ of 10x PCR buffer (Fermantas, Germany), $0.75 \mu \mathrm{L}$ of $\mathrm{MgCl} 2(10 \mathrm{~m} \mu)$ (Fermantas, Germany), 1 $\mu \mathrm{L}$ of dNTP $(10 \mathrm{~m} \mu), 1.75 \mu \mathrm{L}$ of primers with 10 Pmol concentration (Bioneer, Korea), $0.3 \mu \mathrm{L}$ of HOT Taq DNA polymerase $(5 \mathrm{U} / \mu \mathrm{L}), 7 \mu \mathrm{L}$ of DNA $(300 \mathrm{ng} / \mathrm{mL})$, and deionized water were used. In the Master mix, the second round was performed similar to the first one except that 4 $\mu \mathrm{L}$ of DNA was added to the materials as well.

The first round was performed as follows:

The microtubes were put into a thermocycler (Eppendorf, Germany) set for the following program in 35 cycles: pre-denaturation at $95^{\circ} \mathrm{C}$ for 3 minutes, $94^{\circ} \mathrm{C}$ for 30 seconds, annealing at $58^{\circ} \mathrm{C}$ for 40 seconds, and synthesis at $67^{\circ} \mathrm{C}$ for 40 seconds.

For the second round, the nested PCR test was performed in the following order: amplification at $95^{\circ} \mathrm{C}$ for 30 minutes, denaturation at $94^{\circ} \mathrm{C}$ for 30 seconds, annealing at $56^{\circ} \mathrm{C}$ for 40 seconds and at $67^{\circ} \mathrm{C}$ for 40 seconds in 35 cycles and $72^{\circ} \mathrm{C}$ for 5 minutes for the final synthesis.

The final product of PCR was electrophoresed in $2 \%$ agar gel and put in the gel documentation (Vilber, Lourmat, France) device using ethidium bromide and a $517 \mathrm{bp}$ band was detectable.

It should be noted that the ethical considerations in this study were observed as in the other studies (13-18). The data were analyzed in SPSS, version 19. For inferential statistics, the mean and standard deviation were used, and the chi-square test was applied to determine the factors that contributed to $C$. trachomatis infection. The $P<0.05$ was considered as the level of significance.

\section{Results}

The mean age of the subjects was $28.03 \pm 03.18$ ranging from 18 to 35 years. The majority of the women held nonacademic degrees $(n=72,60 \%)$, were employed $(n=79$, $65.83 \%)$, used artificial birth control $(n=69,57.50 \%)$, and had no vaginal discharge $(n=62,51.66 \%)$. In women with positive C. trachomatis infection, sexual intercourse

Table 1. OMP1 Gene Primer Sequence of Chlamydia trachomatis for Nested PCR

\begin{tabular}{ll}
\hline External forward primer & TTG CAA GCT CTG CCT GTG GGG AAT \\
\hline External reverse primer & TCA CAT CGC CAG CTC CAG CAA TAG \\
\hline Internal forward primer & ACA TTA GGA GCC ACC AGT GGA TAT C \\
\hline Internal reverse primer & ATC CTT AGT TCC TGT CGC AGC ATC T \\
\hline $\begin{array}{l}\text { Note. OMP: Outer membrane protein gene; PCR: polymerase chain } \\
\text { reaction. }\end{array}$
\end{tabular}


was mostly more than 4 times a week $(n=9,45 \%)$ while in those with negative $C$. trachomatis infection, it was mainly 2 to 4 times a week $(n=42,42 \%)$. Both infected and non-infected groups were significantly different in terms of employment $(P<0.041)$, birth control method $(P<0.03)$, and the number of sexual intercourses per week $(P<0.001)$. Table 2 represents the distribution of the samples by infected or non-infected subjects divided by the factors associated with spontaneous abortion, which was calculated by the chi-square test.

The current study sought to determine the frequency of C. trachomatis infection in the spontaneous abortion of infertile women who referred to the hospitals affiliated with Tabriz University of Medical Sciences during their first pregnancy by nested PCR method. The rate of infection with $C$. trachomatis in women with spontaneous abortion was $16.66 \%$ in the Nested PCR test. Khezerdoust et al reported a $1.2 \%$ prevalence rate of $C$. trachomatis infection in primiparous women (19), which is much lower than that of the present study. However, it should be noted that unlike this study which focused on infertile women, the above-mentioned study was not limited to a specific group of women which might be the reason for this rather tremendous difference. In a similar study by Ahmadi et al in Sanandaj, an endocervical swab was performed on 218 women and DNA was extracted by the PCR method. Based on their results, C. trachomatis infection was found in $17.43 \%$ of the women with spontaneous abortion (20). The authors referred to $C$. trachomatis infection as one of the influential factors in spontaneous abortions and recommended screening for pregnant women in order to reduce this infection. However, the above-mentioned study did not address infertile women, making our study the first one to explore C. trachomatis infection in Iranian infertile women. In a study by Zahirnia et al in Iran, DNA was extracted from endocervix samples taken by the Dacron swab using the nested PCR method. A number of 16 out of 121 women with spontaneous abortion were infected with C. trachomatis, which is close (13.2\%) to our results (3). The researchers of the present study argued that the prevalence rate of the infection in Iran is similar to those in the neighboring countries but higher than those in the European countries and thus suggested etiological studies to reduce the prevalence of $C$. trachomatis.

Different studies adopted various approaches for investigating C. trachomatis infection. For example, Rashidi et al assessed the chlamydia antibody using the enzyme-linked immunosorbent assay (ELISA) method and studied the urine sample for PCR. They found that chlamydia infection was present in $13.8 \%$ of infertile women (21). It is noteworthy that the amount of chlamydia in the urine sample was very slight and one may argue that the prevalence of the infection should be higher than the amount reported by Rashidi et al thus making their results unrealistic (15). Further, Hashemi et al studied the prevalence of C. trachomatis infection in endocervical samples taken by swab from 123 women using the PCREIA method and reported a $12 \%-25 \%$ prevalence for this infection (22).

Similarly, various studies in different parts of Iran suggest that the prevalence of $C$. trachomatis infection in Tehran, Bandar Abbas, Shiraz, East Azerbaijan, the northwest of Iran, and Mashhad is $22 \%, 10 \%, 6.5 \%, 14 \%, 12.2 \%$ (23), and $14.5 \%$ (24), respectively. Different sampling methods seem to be the cause of varying results in these studies.

Chlamydia trachomatis infection in our study was significantly related to employment, birth control method, and the number of sexual intercourses in a week. Our results are consistent with those of van Bergen et al (25) and Sylvan et al (26). However, since there are no other studies similar to ours, it is irrational to compare our results with those of other studies. Those getting pregnant with unusual methods and assisted reproductive

Table 2. Distribution of the Samples Having or not Having Infection, Divided by the Factors Associated With Spontaneous Abortion

\begin{tabular}{|c|c|c|c|c|}
\hline & Positive $C$. trachomatis $(n=20)$ & Negative $C$. trachomatis $(n=100)$ & $P$ Value & Odds Ratio \\
\hline \multicolumn{5}{|l|}{ Education } \\
\hline Academic & $7(35 \%)$ & $41(41 \%)$ & \multirow[t]{2}{*}{$<0.3$} & \multirow[t]{2}{*}{--} \\
\hline Nonacademic & $13(65 \%)$ & 59 (59\%) & & \\
\hline \multicolumn{5}{|l|}{ Employment } \\
\hline Employed & $6(30 \%)$ & 35 (35\%) & \multirow[t]{2}{*}{$<0.041$} & \multirow[t]{2}{*}{3.3} \\
\hline Unemployed & $14(40 \%)$ & $65(35 \%)$ & & \\
\hline \multicolumn{3}{|c|}{ Birth control method } & \multirow{3}{*}{$<0.03$} & \multirow{3}{*}{3.80} \\
\hline Natural & $8(40 \%)$ & $43(43 \%)$ & & \\
\hline Artificial & $12(60 \%)$ & $57(57 \%)$ & & \\
\hline \multicolumn{5}{|c|}{ Vaginal discharge } \\
\hline Yes & $9(45 \%)$ & 49 (49\%) & \multirow[t]{2}{*}{$<0.31$} & \multirow[t]{2}{*}{--} \\
\hline No & $11(55 \%)$ & $51(51 \%)$ & & \\
\hline \multicolumn{5}{|c|}{ Sexual intercourse per week } \\
\hline$<2$ times & $6(30 \%)$ & $33(33 \%)$ & \multirow{3}{*}{$<0.001$} & \multirow{3}{*}{6.1} \\
\hline 2-4 times & $5(25 \%)$ & $42(42 \%)$ & & \\
\hline$>4$ times & $9(45 \%)$ & 25 (25\%) & & \\
\hline
\end{tabular}


treatments have different infection-affecting factors that would make them prone to these types of infections when compared to the other women. Accordingly, the timely detection of the infection in such women using precise methods like nested PCR is highly essential since failed pregnancy could have negative impacts on the outcomes of future treatments for later pregnancy attempts.

\section{Limitations}

The exclusion of the husbands from the research and the lack of evaluation of the infection before pregnancy are the limitations of the current study. Thus, further research is recommended while compensating for these limitations.

\section{Conclusions}

The prevalence of C. trachomatis was high in women who got pregnant following infertility treatment and experienced spontaneous abortion. In general, the nested PCR test was found to be a precise and appropriate method for the detection of $C$. trachomatis infection and it must be performed for women getting pregnant with the help of infertility treatments. Screening and etiological studies are recommended for future research as well.

\section{Conflict of Interests}

Authors declare that they have no conflict of interests.

\section{Ethical Issues}

This study was approved by the ethical committee of Tabriz University of Medical Sciences (Ethics no: 5/4/6378).

\section{Financial Support}

Tabriz University of Medical Sciences supported the study.

\section{Acknowledgments}

The authors would like to thank the Research Deputy of Tabriz University of Medical Sciences for financial supports, and special thanks go to Dr. Bonyadi for examining the samples.

\section{References}

1. Anttila T, Saikku P, Koskela P, et al. Serotypes of Chlamydia trachomatis and risk for development of cervical squamous cell carcinoma. JAMA. 2001;285(1):47-51. doi:10.1001/ jama.285.1.47

2. Chamani-Tabriz L, Jeddi-Tehrani M, Zeraati $\mathrm{H}$, et al. A molecular survey of Chlamydia trachomatis infection in married women: a cross sectional study on 991 women. Tehran University Medical Journal. 2008;66(7):485-491. [Persian].

3. Zahirnia Z, Eslami G, Goodarzi H, et al. Evaluation of the prevalence of infection with Chlamydia trachomatis in spontaneous abortions, by Nested PCR method. Research in Medicine. 2013;37(1):67-72. [Persian].

4. Svenstrup HF, Fedder J, Kristoffersen SE, Trolle B, Birkelund S, Christiansen G. Mycoplasma genitalium, Chlamydia trachomatis, and tubal factor infertility--a prospective study. Fertil Steril. 2008;90(3):513-520. doi:10.1016/j. fertnstert.2006.12.056

5. Lima HE, Oliveira MB, Valente BG, et al. Genotyping of Chlamydia trachomatis from endocervical specimens in Brazil. Sex Transm Dis. 2007;34(9):709-717. doi:10.1097/01. olq.0000258399.27873.d9

6. Pannekoek Y, Westenberg SM, Eijk PP, et al. Assessment of Chlamydia trachomatis infection of semen specimens by ligase chain reaction. J Med Microbiol. 2003;52(Pt 9):777779. doi:10.1099/jmm.0.05187-0

7. Thomas P, Spaargaren J, Kant R, et al. Burden of Chlamydia trachomatis in India: a systematic literature review. Pathog Dis. 2017;75(5). doi:10.1093/femspd/ftx055

8. Komijani M, Shaykh-Baygloo N, Ghasemi SM, Azad F. A systematic review on the role of infectious agents in female and male infertility. Urmia Medical Journal. 2018;29(4):295304. [Persian].

9. Moradi F, Yousefi Mashouf R, Alikhani MS, et al. Comparison of PCR and culture methods to determine the prevalence of Mycoplasma hominis in woman's endocervical samples referred to Infertility Center of Hamadan Fatemieh Hospital in 2016. The Iranian Journal of Obstetrics, Gynecology and Infertility. 2018;20(11):8392. doi:10.22038/ijogi.2018.10231

10. Goshayeshi L, Vahid Roudsari F, Ghazvini K, Nomani H, Amel Jamehdar S. Pilot prevalence evaluation of Chlamydia trachomatis by PCR in female infertile referred to study center of infertility in Mashhad. Iranian South Medical Journal. 2015;18(1):92-99. [Persian].

11. Kucinskiene V, Sutaite I, Valiukeviciene S, Milasauskiene Z, Domeika M. Prevalence and risk factors of genital Chlamydia trachomatis infection. Medicina (Kaunas). 2006;42(11):885-894.

12. Claas HC, Melchers WJ, de Bruijn IH, et al. Detection of Chlamydia trachomatis in clinical specimens by the polymerase chain reaction. Eur J Clin Microbiol Infect Dis. 1990;9(12):864-868. doi:10.1007/bf01967500

13. Vahedi P, Salehpour F, Aghamohammadi D, et al. Single Dose Preemptive Amitriptyline Reduces Postoperative Neuropathic Pain After Lumbar Laminectomy and Discectomy: A Randomized Placebo-controlled Clinical Trial. Neurosurg Q. 2010;20(3):151-158. doi:10.1097/ WNQ.0b013e3181ebce15

14. Aghamohammadi D, Eidi M, Lotfi A, et al. Effect of low level laser application at the end of surgery to reduce pain after tonsillectomy in adults. J Lasers Med Sci. 2013;4(2):7985.

15. Hosseinzadeh H, Golzari SE, Abravesh M, et al. Effect of low dose dopamine on early graft function in living unrelated kidney donors. Urol J. 2012;9(1):389-396. doi:10.22037/ uj.v9i1.1387

16. Zomorrodi A, Mohammadipoor Anvari H, Kakaei F, Solymanzadeh F, Khanlari E, Bagheri A. Bolus Injection Versus Infusion of Furosemide in Kidney Transplantation: A Randomized Clinical Trial. Urol J. 2017;14(2):3013-3017. doi:10.22037/uj.v14i2.3787

17. Movassaghi R, Peirovifar A, Aghamohammadi D, Mohammadipour Anvari H, Golzari SE, Kourehpaz Z. Premedication With Single Dose of Acetazolamide for the Control of Referral Shoulder Pain After Laparoscopic Cholecystectomy. Anesth Pain Med. 2015;5(6):e29366. doi:10.5812/aapm.29366

18. Bakhshaei $\mathrm{MH}$, Manuchehrian N, Khoshraftar E, 
Mohamadipour-Anvary H, Sanatkarfar M. Analgesic effects of intrathecal sufentanil added to lidocaine $5 \%$ in elective cesarean section. Acta Med Iran. 2010;48(6):380384.

19. Khezerdoust S, Haghollahi F, Roostaie S, Badami N, Naghizadeh M, Jafarabadi M. Chlamydia trachomatis Infection in Pregnant Women. J Reprod Infertil. 2009;10(2):121-129.

20. Ahmadi A, Khodabandehloo M, Ramazanzadeh R, et al. The Relationship between Chlamydia trachomatis Genital Infection and Spontaneous Abortion. J Reprod Infertil. 2016;17(2):110-116

21. Hossein Rashidi B, Chamani-Tabriz L, Haghollahi F, et al. Prevalence of Chlamydia trachomatis infection in fertile and infertile women; a molecular and serological study. J Reprod Infertil. 2009;10(1):32-42.

22. Hashemi FB, Pourakbari B, Yazdi JZ. Frequency of Chlamydia trachomatis in women with cervicitis in Tehran, Iran. Infect Dis Obstet Gynecol. 2009;2009:67014. doi:10.1155/2007/67014

23. Motamedi H, Aria M. The importance of Chlamydia trachomatis serotypes in its infection: a review. The Iranian Journal of Obstetrics, Gynecology and Infertility. 2017;20(6):96-114. doi:10.22038/ijogi.2017.9329

24. Naderinasab M, Genaat J, Rashed T, Ghazvini K. The level of antibody against Chlamydia trachomatisamong patients with genital infections in Mashhad. Iranian Journal of Medical Microbiology. 2007;1(2):35-41. [Persian].

25. van Bergen J, Götz HM, Richardus JH, Hoebe CJ, Broer J, Coenen AJ. Prevalence of urogenital Chlamydia trachomatis increases significantly with level of urbanisation and suggests targeted screening approaches: results from the first national population based study in the Netherlands. Sex Transm Infect. 2005;81(1):17-23. doi:10.1136/ sti.2004.010173

26. Sylvan SP, Von Krogh G, Tiveljung A, et al. Screening and genotyping of genital Chlamydia trachomatis in urine specimens from male and female clients of youthhealth centers in Stockholm County. Sex Transm Dis. 2002;29(7):379-386. doi:10.1097/00007435-20020700000003

(c) 2019 The Author (s); This is an open-access article distributed under the terms of the Creative Commons Attribution License (http://creativecommons.org/licenses/by/4.0), which permits unrestricted use, distribution, and reproduction in any medium, provided the original work is properly cited. 